\title{
Intraparenchymal and Intraventricular Hemorrhage without Mass Effect in Traumatic Coma
}

\author{
Jen-Pei Lee
}

\begin{abstract}
A group of 57-head injured patients showing computerized tomographic (CT) findings compatible with "diffuse brain injury" or of the so called "diffuse axonal injury" is analyzed. Thirty-four patients showed intraparenchymal hemorrhage in the CT scan study, 8 intraventricular hemorrhage and 15 patients had both intraparenchymal and intraventricular hemorrhage. Forty percent $(23 / 57)$ of those with these findings had associated intracranial focal lesions. The deep nuclei are the most common location of intraparenchymal hemorrhage. Signs of brain stem hemorrhage were seen in 9 patients. Forty-nine percent of patients in this series had a good outcome. Old age $(>60)$, abnormal motor response, abnormal eye signs, associated with focal lesions, and evidence of brain stem hemorrhage are reliable prognostic parameters for a grave outcome.
\end{abstract}

RÉSUMÉ: Hémorragie intraparenchymateuse et intraventriculaire sans effet de masse dans le coma traumatique Nous analysons les cas de 57 patients ayant subi un traumatisme crânien et qui présentaient, à la tomographie assistée par ordinateur (CT), des modifications compatibles avec "des lésions cérébrales diffuses" ou "des lésions axonales diffuses". Trente-quatre patients présentaient une hémorragie intraparenchymateuse à l'étude par CT scan, soit 8 patients avec hémorragie intraventriculaire et 15 avec hémorragie intraparenchymateuse et intraventriculaire. $40 \%$ (23/57) de ces patients avaient des lésions focales intracrâniennes associées. Les noyaux de la base sont le site le plus fréquent d'hémorragie intraparenchymateuse. Des signes d'hémorragie du tronc cérébral ont été observés chez 9 patients. $49 \%$ des patients dans cette étude ont eu une issue favorable. Un âge avancé ( $>60$ ans), une réponse motrice anormale, des signes oculaires anormaux, des lésions focales associées et des manifestations d'une hémorragie du tronc cérébral sont des paramètres fiables indiquant un pronostic sombre.

Can. J. Neurol. Sci. 1991; 18: 458-462

Diffuse axonal injury (DAI) is a well known entity that affects many patients with severe head trauma. Classically, DAI has been considered the pathological substrate of those cases rendered unconscious at the moment of impact and in which the CT scan does not show a mass lesion. DAI was first described in non-missile head injury by Strich in 1956.' This pathological concept was expanded by Adams and coworker in further studies. ${ }^{2-4}$ Gennarelli et al.,56 reproduced this type of lesion in subhuman primates by using non-impact, controlled angular acceleration of the head. Its CT presentation may range from a normal $\operatorname{scan}^{7}$ to the picture of small hemorrhage in the corpus callosum, the internal capsule, the periventricular gray matter and posterolateral upper part of the brain stem. ${ }^{8}$

There is no diagnostic procedure that is capable of determining the amount and extent of axonal damage in patients with DAI. This study was designed to correlate the clinical picture, radiological findings and the prognosis of this group of patients.

\section{Clinical. Materials and Methods}

This is a retrospective analysis of 57 patients between June 1983 and June 1986 with CT signs of so-called DAI after a closed head injury. It represents $2.1 \%$ of patients who received a CT scan after a head injury and $9.3 \%$ of our total series of severe head injuries during that period. Patients were considered to have a severe head injury when they were unable to open their eyes to painful stimuli, to speak, and to obey commands for at least 6 hours after the injury, or subsequent deterioration. There were 51 men and 6 women with ages ranging from 4 to 73 years (average 34.6 years). Injury was sustained in a motorcycle accident in 48 cases (84\%), after a car accident in $8(14 \%)$ and after a fall in one.

The CT imaging criteria for defining so-called DAI in the present study were the presence of small intraparenchymal hemorrhage (IPH) and/or intraventricular hemorrhage (IVH) in the

From the Division of Neurosurgery, Department of Surgery, Chang Gung Medical College and Chang Gung Memorial Hospital, Taipei, Taiwan Received November 2 1990. Accepted in final form February 12, 1991

Reprint requests to: Dr. Jen-Pei Lee, Division of Neurosurgery, Taiwan Provincial Tao-Yuan General Hospital 1492, Chung-Shan Road, Tao-Yuan Taiwan 33007 R.O.C. 
absence of a focal mass effect or midline displacement. No history of a hemorrhagic tendency was obtained in any of these patients, and no bleeding tendency was noticed at the site of intravenous transfusion. Bleeding time, prothrombine time, activated partial thromboplastin time, fibrinogen and platelet were normal in this series.

Patients were put on volume-limiting ventilators, when ventilatory support was required. An average $\mathrm{PaCO} 2$ of 25 to 30 $\mathrm{mmHg}$ and an arterial PO2 over $80 \mathrm{mmHg}$ were maintained. Intracranial hypertension was vigorously treated with mannitol. Neither barbiturate therapy nor extensive decompressive craniectomy was used. Intracranial pressure monitoring was not standardized. Surgical evacuation of another concomitant or delayed intracranial hemorrhage was done in three patients (one for epidural, one for subdural, and one for hydrocephalus).

Clinical evaluation of patients was done according to the Glasgow coma scale (GCS) ${ }^{9}$ and their outcome was evaluated at least one year after the injury and graded using the scale of Jennett and Bond. ${ }^{10}$

\section{Results}

The prognosis in this series was rather good. $28(49 \%)$ patients made a functional recovery (Table 1 ). Seven $(12 \%)$ remained in a severely disabled state but were able to care for themselves, seven $(12 \%)$ were in a vegetative state and fifteen $(26 \%)$ died.

\section{Outcome related to age}

Post-traumatic IPH and/or IVH was more frequent during the 3rd and 4th decade of life; $56 \%$ of all patients were in this age group (Table 1). All the patients who made a functional recovery were younger than sixty years. The mean age for patients with a good outcome was 28.3 years, compared with 44.5 years for those who died or remained in a vegetative state.

\section{Outcome related to neurological status}

\section{Best motor response}

The abnormal motor response category included decortication, decerebration and absent response to pain (flaccid). This feature showed a strong association with a poor result in the whole series (Table 2). $78 \%$ of patients who were posturing or

\begin{tabular}{|c|c|c|c|c|c|c|c|}
\hline \multirow[t]{2}{*}{ Age } & \multicolumn{5}{|c|}{ Outcome } & \multirow{2}{*}{$\begin{array}{c}\text { Case } \\
\text { No. }\end{array}$} & \multirow[t]{2}{*}{$\%$} \\
\hline & GR & MD & SD & PVS & D & & \\
\hline $0-9$ & & & 1 & & & 1 & 1.8 \\
\hline $10-19$ & 4 & 1 & & & & 5 & 8.8 \\
\hline $20-29$ & 8 & 3 & 4 & 2 & 3 & 20 & 35.1 \\
\hline $30-39$ & 6 & 2 & 1 & 1 & 2 & 12 & 21.1 \\
\hline $40-49$ & 2 & 1 & & & 2 & 5 & 8.8 \\
\hline $50-59$ & 1 & & & 1 & 2 & 4 & 7.0 \\
\hline $60-69$ & & & & 2 & 5 & 7 & 12.3 \\
\hline $70-79$ & & & 1 & 1 & 1 & 3 & 5.3 \\
\hline
\end{tabular}

GR: Good recovery

SD: Severe disability

D: Death

Graded by the categories of Jennett and Bond ${ }^{10}$ flaccid on admission died or were left in a vegetative state, while only $14 \%$ of those who had a more organized motor response on admission ended in these categories $(\mathrm{P}<0.05)$.

\section{Oculocephalic response}

There was a strong correlation between the state of the oculocephalic response on admission and final outcome (Table 3). $79 \%$ of those with impaired or absent oculocephalic response had a bad result, while only $26 \%$ of those who had normal oculocephalic response died or were left in a vegetative state $(\mathrm{P}<0.05)$.

\section{Pupillary light reflex}

There was a strong correlation between impairment or absence of the pupillary light response and poor outcome from the injury (Table 3). $78 \%$ of 18 patients with abnormal pupillary light response died or remained vegetative; in comparison, $21 \%$ of patients who had normal pupillary light responses fell into these categories $(\mathrm{P}<0.05)$.

Table 2: The Best Motor Response to Pain Stimuli Related to Final Outcome

\begin{tabular}{lccccccc}
\hline \hline $\begin{array}{l}\text { Best Motor } \\
\text { Response }\end{array}$ & \multicolumn{4}{c}{ Outcome } & \multicolumn{3}{c}{$\begin{array}{c}\text { Case } \\
\text { No. }\end{array}$} \\
\cline { 2 - 6 } & GR & MD & SD & PVS & D & & \\
\hline Localize pain & 17 & 5 & 2 & & 4 & 28 & 49.1 \\
Withdrawal & 3 & 2 & 3 & 1 & 7 & 16 & 28.1 \\
Decorticate & 1 & & 1 & 1 & & 3 & 5.3 \\
Decerebrate & & & & 4 & 1 & 5 & 8.8 \\
Flaccid & & & 1 & 1 & 3 & 5 & 8.8 \\
\hline
\end{tabular}

GR: Good recovery

SD: Severe disability

MD: Moderate disability

D: Death

PVS: Persistent vegetative state

Graded by the categories of Jennett and Bond ${ }^{10}$

Table 3: Eye Reaction Related to Final Outcome

\begin{tabular}{|c|c|c|c|c|c|c|c|}
\hline \multirow[t]{2}{*}{ Eye Reaction } & \multicolumn{5}{|c|}{ Outcome } & \multirow{2}{*}{$\begin{array}{l}\text { Case } \\
\text { No. }\end{array}$} & \multirow[t]{2}{*}{$\%$} \\
\hline & GR & MD & SD & PVS & D & & \\
\hline Normal & 19 & 7 & 5 & 4 & 4 & 39 & 68.4 \\
\hline \multicolumn{8}{|l|}{$\begin{array}{c}\text { Unilateral mydriasis } \\
\text { without L-R }\end{array}$} \\
\hline Doll eye $(+)$ & 1 & & & 1 & & 2 & 3.5 \\
\hline Doll eye (-) & & & 2 & & 3 & 5 & 8.8 \\
\hline \multicolumn{8}{|l|}{$\begin{array}{l}\text { Bilateral miosis } \\
\text { without L-R }\end{array}$} \\
\hline Doll eye $(+)$ & & & & & 1 & 1 & 1.8 \\
\hline Doll eye (-) & & & & 1 & 2 & 3 & 5.3 \\
\hline \multicolumn{8}{|l|}{$\begin{array}{c}\text { Dilateral mydriasis } \\
\text { without } \mathrm{L}-\mathrm{R}\end{array}$} \\
\hline Doll eye (+) & & & & & 1 & 1 & 1.8 \\
\hline Doll eye (-) & 1 & & & 1 & 4 & 6 & 10.5 \\
\hline
\end{tabular}

L-R: Light reflex

GR: Good recovery

SD: Severe disability

+: Present

-: Absent

D: Death

PVS: Persistent vegetative state

Graded by the categories of Jennett and Bond 10 


\section{Combination of adverse signs}

In patients with abnormal motor response, impaired or absent oculocephalic response, and absence of pupillary light reaction $89 \%$ died or remained in a vegetative state. However only $16 \%$ $(9 / 57)$ of the total patients had this combination of signs.

\section{Outcome related to radiological findings}

Associated extracranial lesions were found in twenty-one patients $(37 \%)$, mostly with skeletal injury. They did not contribute to the final outcome. Skull fracture, which was present in only six patients $(11 \%)$, did not correlate with the severity of injury as assessed by the GCS score or the final outcome.

Associated intracranial focal lesions were demonstrated in 24 patients $(40 \%)$ (Table 4 ); 18 cases with contusion hemorrhage, five with subdural hematoma, one with epidural hematoma. $76 \%$ of those patients with focal lesions had a bad outcome (dead or vegetative), in comparison to $27 \%$ of those without focal lesions died or remained in a vegetative state $(\mathrm{P}<0.05)$.

Thirty-four patients showed IPH, 8 IVH and 15 both IPH and IVH in the CT scan study (Table 5). Intraventricular hemorrhage (Figure 1), which was preferentially located in the lateral and third ventricle, resulted in acute hydrocephalus in only one case. Fifteen patients showed one or more hemorrhagic foci in the deep white matter of the cerebral hemisphere, usually in the internal capsule or adjacent to the basal ganglia (Figure 2). Hemorrhage, when bilateral, was always asymmetrical. Forty-

Table 4: Associated Intracranial Focal Lesion Related to Final Outcome

\begin{tabular}{lcccccccc}
\hline \hline $\begin{array}{l}\text { Associated Intra- } \\
\text { cranial lesion }\end{array}$ & \multicolumn{4}{c}{ Outcome } & \multicolumn{3}{c}{$\begin{array}{c}\text { Case } \\
\text { No. }\end{array}$} \\
\cline { 2 - 6 } & GR & MD & SD & PVS & D & \\
\hline EDH & & 1 & & & & 1 & 1.8 \\
SDH & & 1 & 1 & 1 & 2 & 5 & 8.8 \\
$\begin{array}{l}\text { Contusion } \\
\quad \text { hemorrhage }\end{array}$ & 3 & 2 & 3 & 3 & 7 & 18 & 31.6 \\
Nil & 18 & 3 & 3 & 3 & 6 & 33 & 57.9 \\
\hline
\end{tabular}

EDH: Epidural hematoma

SDH: Subdural hematoma

GR: Good recovery

SD: Severe disability

MD: Moderate disability

PVS: Persistent vegetative state

D: Death

Graded by the categories of Jennett and Bond 10

Table 5: Computed Tomographic Findings Related to the Final Outcome

\begin{tabular}{lrrrrrrrr}
\hline \hline CT Findings & \multicolumn{4}{c}{ Outcome } & \multicolumn{3}{c}{$\begin{array}{c}\text { Case } \\
\text { No. }\end{array}$} \\
\cline { 2 - 6 } & GR & MD & SD & PVS & D & \\
\hline IPH & 16 & 4 & 5 & 2 & 7 & 34 & 59.6 \\
IVH & 4 & & 1 & 1 & 2 & 8 & 8.8 \\
IPH+IVH & 1 & 3 & 1 & 4 & 6 & 15 & 26.3 \\
\hline
\end{tabular}

IPH: Intraparenchymal hemorrhage IVH: Intraventricular hemorrhage GR: Good recovery

SD: Severe disability

MD: Moderate disability

D: Death

PVS: Persistent vegetative state

Graded by the categories of Jennett and Bond 10 five patients had small hemorrhages in the deep nuclei (Figure 3). Only two patients showed hemorrhage in the corpus callosum. The location and number of IPH and its relation to the final outcome is reported in Table 6. It was expected that the higher the number of hematomas, the poorer would be the course, but the final outcome did not show a significant difference.

Brain stem hemorrhagic contusion was observed in 9 cases (Figure 4). Five of these patients showed lesion in the pons, the other four in the midbrain. Two of them had a good outcome, 3 were severely disabled, 2 remained vegetative, and 2 died.

\section{Discussion}

Diffuse brain injury (DBI) and diffuse axonal injury (DAI) are almost interchangeable terms that are frequently used to define those patients in coma without mass lesion.1-7,11,12

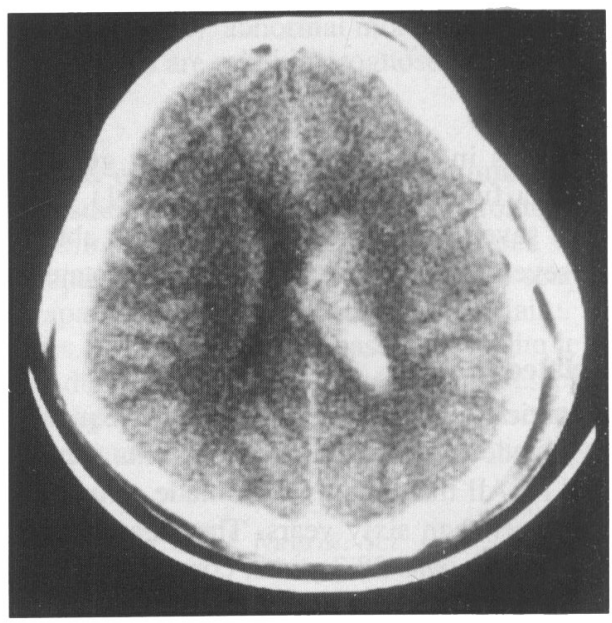

Figure 1 - Unenhanced computerized tomographic scan of a patient showing intraventricular hemorrhage. Hemorrhage in the corpus callosum was also noted. The patient died.

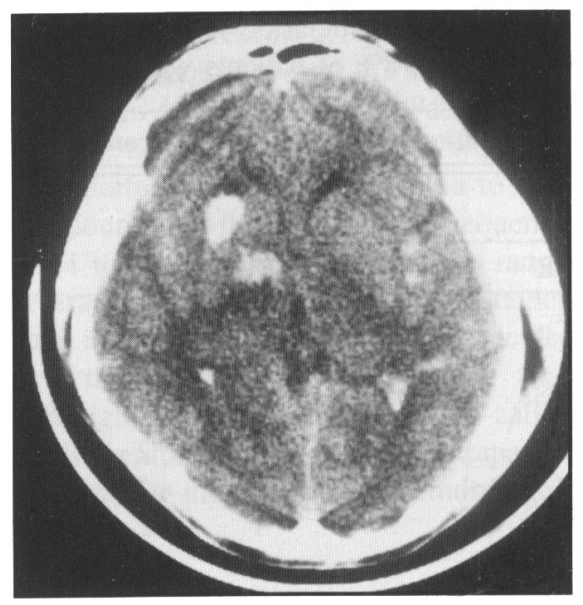

Figure 2 - Unenhanced computerized tomographic scan of a patient showing multiple hemorrhagic foci in the deep white matter or adjacent to the basal ganglia. The patient died within 48 hours after trauma. 
Widespread axonal damage is the pathological substrate found in most of these cases. DAI is produced by physical forces that are engendered at the moment of impact.3,6 These shearing force were predicted by Holbourn ${ }^{13}$ thirty years ago and are frequently produced in angular acceleration injury. ${ }^{6}$ Gennarelli, using non-impact acceleration model, has reproduced in the laboratory the entire spectrum of brain lesions found in head injury including DAI and acute subdural hematoma.5,6,14 The term diffuse brain injury may be used to describe those patients rendered immediately unconscious on impact and who do not show mass lesions on the admission CT scan. The term DAI should be reserved for all those cases in whom the postmortem examination disclosed macroscopic features of diffuse axonal injury (corpus callosum hemorrhage, dorsolateral rostral brain stem hemorrhage, and other hemorrhages) and/or widespread microscopic white matter damage.

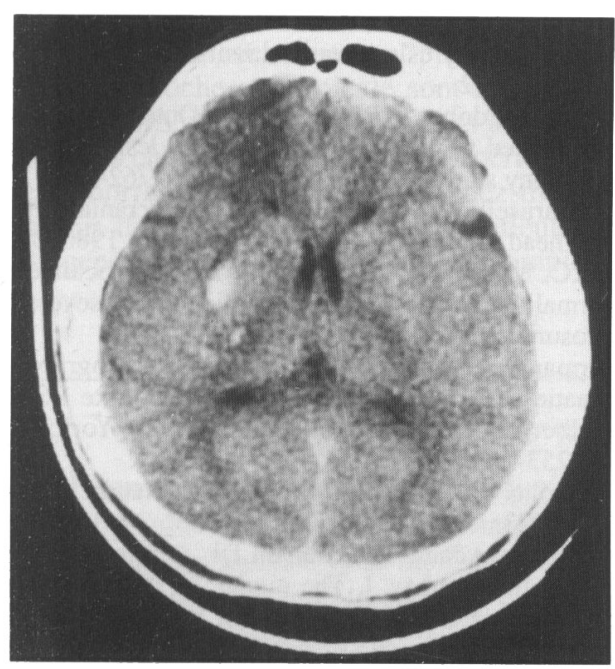

Figure 3 - Unenhanced computerized tomographic scan of a patient showing hemorrhage in the basal ganglia. The patient made a good recovery.

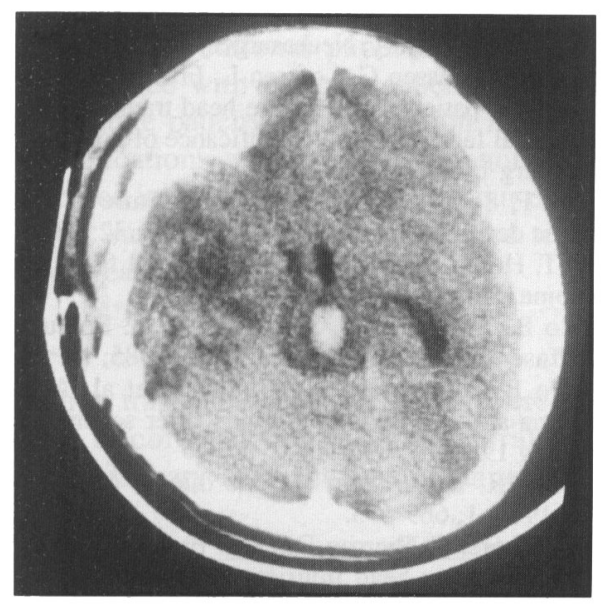

Figure 4-Unenhanced computerized tomographic scan of a patient showing hemorrhage in the brain stem. The patient remained with a severe disability.
The proportion of cases classified as suffering DBI or DAI in severe head injury series range from 35 to $74 \%$, when patients with either a normal CT scan or so-called generalized brain swelling, are included. $15-19$ We have analyzed only those cases showing the typical CT finding of DAI as described by Zimmerman et al. ${ }^{8}$ We included 8 patients showing intraventricular hemorrhage as the only finding. Several studies have indicated that the overwhelming majority of head injury patients showing intraventricular bleeding also have shearing injury of the white matter. $7,8,20$ Various necropsy studies of patients with DAI have revealed the association of corpus callosum and subependymal hemorrhage to be a common finding. 2,21 Zimmerman and Bilaniuk found intraventricular hemorrhage in $4(30 \%)$ out of 13 patients with diffuse shearing injury, ${ }^{20}$ and Snoek et al. in $2(33 \%)$ out of 6 cases. $^{7}$

Most patients with DBI have sustained cranial trauma in traffic accidents, ${ }^{2-3,20}$ and only a minority have a skull fracture. ${ }^{3}$ Ninety-eight percent of patients in this series were involved in traffic accident and only $11 \%$ had a skull fracture. The phenomenon of marked preponderance of traffic accidents and low incidence of falls was also noted by Zimmerman et al. 8 Experimental studies indicate that greater force is required to initiate shear strain in a fixed head than a head that is freely moveable.22,23 Rotatory acceleration of the head is much more likely to occur during a traffic accident than during a fall, when the skull is relatively stationary at the moment of impact.

Several authors place great stress on the deleterious influence of advancing age on outcome from head injury. ${ }^{24,25}$ Yet Jennett et al. ${ }^{26}$ noted that in their large series that age significantly influenced mortality only below 20 years and over 60 years. Decade by decade analysis of the intervening periods showed age to be of lesser importance. Carlsson and his colleagues ${ }^{27}$ noted that all of the age-related increase in mortality was due to systemic medical complications. In the present series, none of the patients older than 60 years had a good outcome.

Table 6: Location and Number of IPH in 57 Patients Related to the Final Outcome

\begin{tabular}{lrrrrrrr}
\hline \hline & \multicolumn{9}{c}{ Outcome } & \multicolumn{3}{c}{$\begin{array}{c}\text { Case } \\
\text { No. }\end{array}$} \\
\cline { 2 - 6 } & GR & MD & SD & PVS & D & \\
\hline Location of IPH & & & & & & & \\
$\quad$ Deep nuclei & 15 & 6 & 6 & 6 & 12 & 45 & 78.9 \\
Deep white matter & 4 & 2 & 4 & 3 & 2 & 15 & 26.3 \\
Corpus callosum & 1 & & & 1 & & 2 & 3.5 \\
Brain stem & 2 & & 3 & 2 & 2 & 9 & 15.8 \\
No. of IPH & & & & & & & \\
1 & 9 & 5 & 1 & 1 & 10 & 26 & 45.6 \\
2 & 5 & 1 & 2 & 1 & 1 & 10 & 17.5 \\
3 & 3 & & 2 & 2 & & 7 & 12.3 \\
4 & & 1 & 1 & & 1 & 3 & 5.3 \\
$>4$ & & & & 2 & 1 & 3 & 5.3 \\
\hline
\end{tabular}

IPH: Intraparenchymal hemorrhage GR: Good recovery

SD: Severe disability

MD: Moderate disability D: Death

Graded by the categories of Jennett and Bond 10 
The presence of a lucid interval in DAI is still a controversial topic. In our series, all patients were rendered unconscious immediately on impact. No patients in Adams' group had a lucid interval.2-4 Some authors have reported the existence of partial or complete lucid intervals in cases of diffuse axonal injury. ${ }^{21}$ We have found, as have others, that loss of pupillary light response, impairment of reflex oculomotor function, and abnormal motor response to painful stimuli all portend a markedly worse prognosis for the group of patients in whom these signs are present. 24,25,28,29

Coexistence of DAI with focal lesions has been reported. 3,30;31 The presence of DAI could play an important role in head-injured patients with immediate impact coma and poor outcome. ${ }^{30,31}$ It also has been observed that patients who show hemorrhagic intracranial lesions on CT scan have a worse outcome than patients who do not. This finding suggests that brain damage is more severe in the group of patients with focal lesions. Our study also has the same findings.

In the 100 fatal head injury cases with histological criteria of DAI analyzed by Pilz, the most severe clinical picture occurred in patients showing damage to both the corpus callosum and the superior cerebellar peduncle. ${ }^{21}$ The only patient in the present series showing these two lesions remained in a vegetative state. Brain stem hemorrhage was the single finding carrying the worst prognosis; only 2 of the patients with this lesion made a favorable recovery. Brain stem hemorrhage has been associated with an adverse outcome in other severe head injury series. ${ }^{32-34}$ Adams et al. suggested that primary brain stem injury is only one of the components of the primary white matter damage of impact type, and never occurs in isolation. ${ }^{2}$ Only two of our patients had an isolated brain stem lesion visible in the CT scan, the remaining cases showed associated cerebral white matter or intraventricular hemorrhage.

In conclusion, IPH and/or IVH occurred in $9.3 \%$ of severe head injured patients in our series. This type of lesion may attain different degrees of severity. Old age $(>60)$, abnormal eye signs, abnormal motor response, and associated focal lesions indicated a poor outcome. Brain stem hemorrhage is the CT finding indicating the worst prognosis.

\section{ACKNOWLEDGEMENT}

The author would like to thank Miss Yun Shu for her secretarial assistance.

\section{REFERENCES}

1. Strich SJ. Diffuse degeneration of the cerebral white matter in severe dementia following head injury. J Neurol Neurosurg Psychiatry 1956; 19: 163-185,

2. Adams JH, Mitchell DE, Graham DI, et al. Diffuse brain damage of immediate impact type, its relationship to "primary brain-stem damage" in head injury. Brain 1977; 100: 489-502.

3. Adams JH, Graham DI, Murray LS, et al. Diffuse axonal injury due to nonmissile head injury in humans: an analysis of 45 cases. Ann Neurol 1982; 12: 557-563.

4. Adams JH, Doyle D, Graham DI, et al. Diffuse axonal injury in head injuries caused by a fall. Lancet 1984; $2: 1420-1422$.

5. Gennarelli TA. Head injury in man and experimental animals: clinical aspects. Acta Neurochir (Wien) 1983; (suppl 32): 1-13.

6. Gennarelli TA, Thibault LE, Adams JH, et al. Diffuse axonal injury and traumatic coma in the primate. Ann Neurol 1982; 12: 564574 .
7. Snoek J, Jennett B, Adams JH, et al. Computerized tomography after recent severe head injury in patients without acute intracranial hematoma. J Neurol Neurosurg Psychiatry 1979; 42: 215-225.

8. Zimmerman RA, Bilaniuk LT, Gennarelli T. Computed tomography of shearing injuries of the cerebral white matter. Radiology 1979; 127: 393-396.

9. Teasdale G, Jennett B. Assessment of coma and impaired consciousness: a practical scale. Lancet 1974; 2: 81-84.

10. Jennett $B, B$ Bnd $M$. Assessment of outcome after severe brain damage: a practical scale. Lancet $1975 ; 1: 480-484$.

11. Adams JH, Graham DI, Scott G, et al. Brain damage in fatal nonmissile head injury. J Clin Pathol 1980; 33: 1132-1145.

12. Peerless SJ, Rewcastly NB. Shear injuries of the brain. Can Med Assoc J 1967; 5: 577-582.

13. Holbourn AHS. Mechanics of head injuries. Lancet 1943; 2: 438441.

14. Gennarelli TA, Thibault LE. Biomechanics of acute subdural hematoma. J Trauma 1982; 33: 680-686.

15. Becker DP, Miller JD, Ward JD, et al. The outcome from severe head injury with early diagnosis and intensive management. $J$ Neurosurg 1977; 491-502.

16. Gennarelli TA, Spielman GM, Langfitt TW, et al. Influence of the type of intracranial lesion as outcome from severe head injury. A multicenter study using a new classification system. J Neurosurg 1982; 56: 26-32.

17. Lobato RD, Lordobes F, Rivas JJ, et al. Outcome from severe head injury related to the type of intracranial lesion. A computerized tomography study. J Neurosurg 1983; 59: 762-774.

18. Papo L, Caruselli G, Scarpelli M, et al. Intracranial hypertension in severe head injuries. Acta Neurochir (Wien) 1980; 52: 249-263.

19. Sweet RC, Miller JD, Lipper M, et al. Significance of bilateral abnormalities on the CT scan in patients with severe head injury. Neurosurgery $1978 ; 3: 16-21$.

20. Zimmerman RA, Bilaniuk LT. Computed tomography in diffuse traumatic cerebral injury. In: Popp AJ, Bourke RS, Nelson LR, Kimelberg HK, eds. Neural Trauma. New York: Raven Press, $1977 ; 253-262$.

21. Pilz P. Axonal injury in head injury. Acta Neurochir (Wien) 1983; 32: 119-123.

22. Gennarelli TA, Adams JH, Graham DI. Acceleration induced head injury in the monkey. I. The model, its mechanical and physiological correlate. Acta Neuropathol (Berl) (suppl) 1981; 7: 2325.

23. Denny-Brown D, Russell WR. Experimental cerebral concussion. Brain 194; 64: 93-164.

24. Pagni CA. The prognosis of head-injured patients in a state of coma with decerebrated posture. J Neurol Sci 1973; 17: 289-295.

25. Stewart WA, Litten SP, Sheehe PR. A prognostic model for brain stem injury. Surg Neurol 1973; 1: 303-310.

26. Jennett B, Teasdale G, Braakman R, et al. Prognosis of patients with severe head injury. Neurosurgery 1979; 4: 283-289.

27. Carlsson CA, VonEssen C, Lofaren L. Fractors affecting the clinical course of patients with severe head trauma. Part 1: influence of biological factors. Part 2: significance of post-traumatic coma. J Neurosurg 1968; 29: 248-251.

28. Gutterman P, Shenkin HA. Prognostic feature in recovery from traumatic decerebration. J Neurosurg 1970; 32: 330-335.

29. Richards T, Hoff J. Factors affecting survival from acute subdural hematoma. Surgery $1974 ; 75: 253-258$.

30. Sahuquillo BJ, Lamarca CJ, Vilalta CJ, et al. Epidural hematoma and diffuse axonal injury. Neurosurgery 1985; 17: 378-379.

31. Sahuquillo BJ. Lamarca CJ, Vilalta CJ, et al. Acute subdural hematoma and diffuse axonal injury after severe head trauma. $J$ Neurosurg 1988; 68: 894-900.

32. Crompton MR. Brain stem lesions due to closed head injury. Lancet 1971; 1: 669-673.

33. George B, Thorel C, Pierron D, et al. Frequency of primary brain stem lesions after head injuries, a CT scan analysis from 186 cases of severe head trauma. Acta Neurochir (Wien). 1981; 59: 35-43.

34. Tsai FY, Teal JS, Quinn MF, et al. CT of brain stem injury. Am J Neuroradiol 1980; 1: 23-29. 